\title{
AC 2008-2674: IMPACT OF SHADING ON COOLING AND HEATING LOAD
}

Narciso Macia, Arizona State University

Narciso F. Macia is an Associate Professor in the Department of Electronic Systems, at Arizona State University at the Polytechnic campus (formerly ASU East). He received B.S. and M.S. degrees in mechanical engineering in 1974 and 1976 from the University of Texas at Arlington. He also received a Ph.D. in electrical engineering from Arizona State University in 1988. He is a Registered Engineer in the State of Arizona.

\section{John-Paul Ishioye, Arizona State University}

John-Paul Ishioye graduate research assistant at ASU-PTL, Arizona State University Photovoltaic Testing Laboratory. He has a Bachelors degree in Electronics Engineering Technology from University of Missouri Central. He is currently completing his Master's degree in Alternative Energy Technologies at ASU. ASU-PTL is the only accredited design qualification laboratory in the United States. ASU-PTL has tested more than 3000 PV modules and issued more than 280 qualification certificates. ASU-PTL participates in the development of national and international standards of ASTM, IEEE and IEC.

\section{Brigid Dotson, University of Washington}

Brigid Dotson is an atmospheric scientist living in Seattle, WA. She graduated summa cum laude with a B.S. in Geography with a concentration in Meteorology from Arizona State University in 2004. In 2007, she graduated with a M.S. degree in Atmospheric Science from the University of Washington in Seattle, WA. Her undergraduate work focused on human-environment topics, water resources in southern Arizona, and strange weather phenomena. Her graduate work focuses on Pacific Northwest weather, specifically high wind events in the Puget Sound region.

\section{Maria Macia, Veritas Preparatory Academy}

Maria Macia received a BA in Economics and Political Science from Swarthmore College in 2007. She is currently teaching high school math and humane letters at Veritas Preparatory Academy in Phoenix, Arizona. 


\title{
Impact of Shading on the Cooling and Heating Loads of a Typical Residential
}

\section{Building}

\author{
Narciso F. Macia, John Paul Ishioye, Brigid \\ Dotson, Maria Macia \\ Electronic Systems Department \\ Arizona State University at the Polytechnic \\ campus
}

\begin{abstract}
This paper explores the implications of shading the roof of a residence on the cooling and heating loads. This is done by simulating a thermal model of a hypothetical $2800 \mathrm{sq}$. $\mathrm{ft}$ house which takes into consideration direct and diffuse solar irradiation on its roof and walls. The simulation is performed for a home in the southwest portion of the United States, specifically, Phoenix. The simulation is performed twice: a) with half of the roof shaded with PV modules mounted on a rack, and b) with no PV modules. Even though the specific device used here to provide the shading is PV arrays, any other means would produce similar results. The dynamic thermal model of the house is implemented in TK-Solver. The simulation goes through every hour to determine the required cooling and heating load. It takes into consideration direct and diffuse solar irradiance. It uses the Sol-Air temperature approach to determine wall and roof temperatures. This approach modifies the outside skin temperature depending on direct and diffuse irradiation. Weather data for Phoenix, for the year 1990, is used in the simulation. The simulation results are used to perform an economic analysis, specifically, the impact on the payback period. The yearly cooling costs are reduced by $\$ 126$, while the heating cost increases by $\$ 25$. Thus the shading produced by the PV arrays has a net effect of reducing the yearly electric bill by approximately $11 \%$. A major motivation for this study is to expose students to the tools and methodologies of modeling dynamic physical systems, especially in the energy area.

Introduction

In the southwest of the United States, cooling load accounts for a large portion of the total utility bill. Similarly PV arrays continue to play an increasing role in green or environment-friendly houses. This is the result of genuine concern for the environment, reduced pay-off periods caused by decreasing PV array prices and attractive government incentives. PV is particularly attractive in the southwest because of an overabundance of sunlight. Even though PV contribution is unquestioned, in real practice it has not achieved the popularity that some had expected. The main reason for this is cost, and the resulting long payoff period. Even after generous state and federal incentives, the payoff period remains around15 years. Shading has an obvious impact on
\end{abstract}


the cooling load. Its effect has been investigated in many cases. For example Lam investigates the effect of surrounding buildings on producing shade [1].

This paper is also used as a teaching vehicle in the senior capstone class, in which the students are working on a design project that includes heat gain/losses in a small greenhouse, the use of PV modules to charge a battery and also drive a small, centrifugal pump.

Thermal model

It is important to use a model that has the ability to handle the heat storage properties of the building. For instance, if the night is particularly cold, the building model should reflect the coldness of the night and yield a building that is initially cold on the following day, one that will demand less cooling. The model schematic for the house used in this analysis is shown in Figure 1. It describes a thermal mass at temperature $T_{i}$ surrounding by an insulating material, the entire house is then surrounded by an outside temperature $T_{o}$. Notice that the house would experiences no solar radiation on its south-facing roof if was covered with PV modules.

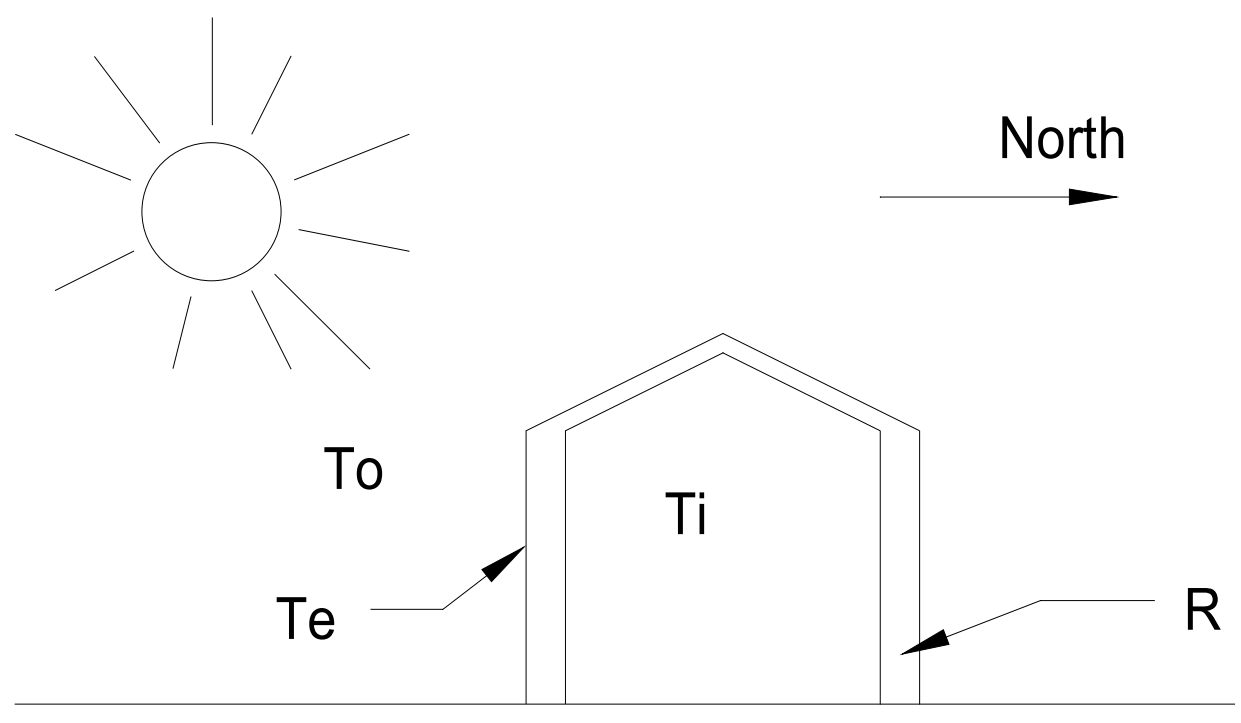

Figure 1: Model schematic for thermal model of home

Sol-Air Temperature

$\mathrm{A} / \mathrm{C}$ and Heating engineers have developed a methodology that permits them to take into account solar irradiation in heat transfer mechanisms associated with heating/cooling loads calculations [2]. The heat flux passing through an exterior, sunlit surface is given by:

$$
\frac{q}{A}=\alpha E_{t}+h_{0}\left(T_{o}-T_{i}\right)-\varepsilon \Delta R(0.1)
$$

where: 
$\alpha=$ abssorptance of surface for solar radiation

$E_{t}=$ total solar radiation incident on the surface

$h_{0}=$ coefficient of heat transfer by long - wave radiation and convection at outer surface

$T_{o}=$ outdoor air temperature

$T_{i}=$ inside wall surface temperature

$\varepsilon=$ hemispherical emmitance of surface

$\Delta R=$ difference between long - wave radiation incident on surface from sky and surroundings and radiation emitted by blackbody at outdoor air temperature

Thus the resulting heat-flux can be expressed in terms of the Sol-Air temperature, $T_{e}$ :

$$
\frac{q}{A}=h_{0}\left(T_{e}-T_{i}\right)
$$

Combining the previous two equations and expression for the Sol-Air temperature is obtained:

$$
T_{e}=T_{o}+\frac{\alpha E_{t}}{h_{0}}-\frac{\varepsilon \Delta R}{h_{0}}
$$

For horizontal surfaces that only receive long-wave radiation, the last term of the equation has a magnitude of $7^{\circ} \mathrm{F}$ [2]. This explains why car surfaces are often covered with frost during the early hours of the morning, even though the night temperature never dropped below freezing. Vertical surfaces behave differently, since they receive long-wave radiation not only from the sky, but also from surrounding buildings and the ground. In such case, values for $\Delta R$ are difficult to determine [2]. Consequently, the last term of the equation is assumed to be zero. In this study, we assume that the roofs act more like horizontal surfaces rather than vertical surfaces. This model assumes that the heat transfer coefficient for convection is constant. In reality this coefficient depends on wind velocity.

Thus, one can represent the lumped-parameter, thermal model capturing the thermal dynamic characteristics of the systems by means of an electrical circuit [3], shown in Figure 2. $C$ is the equivalent thermal mass of the house (also called lumped thermal capacitance) and $R$ represents the equivalent thermal resistance. No convection is considered inside the house. Applying Kirchhoff's Current law, results in: 


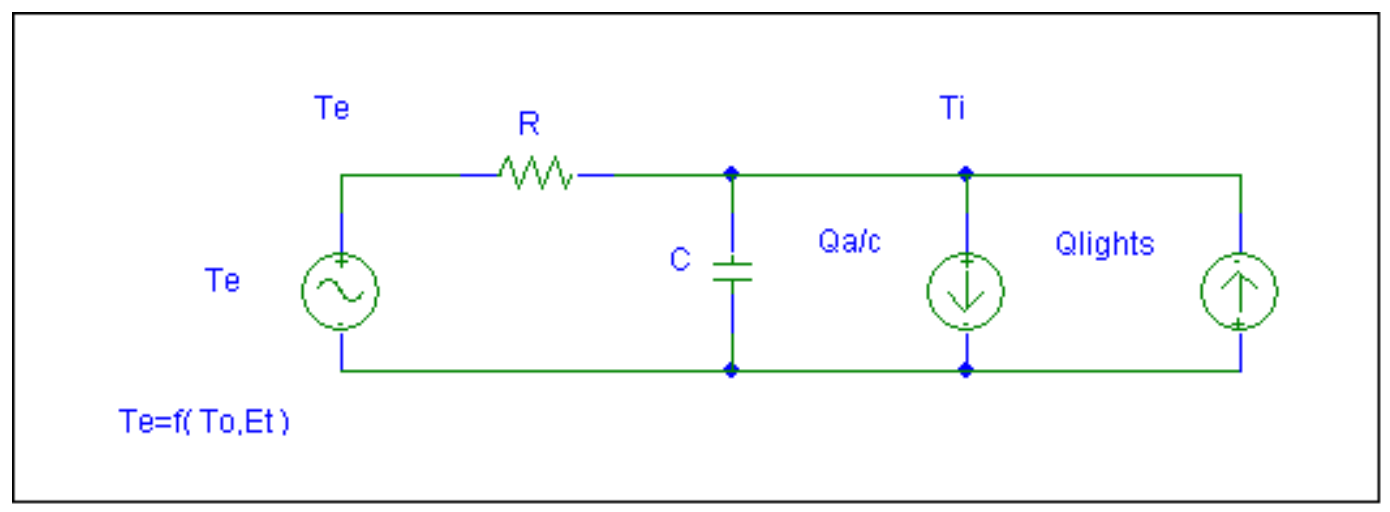

Figure 2: Electric circuit equivalent for the thermal house model

$$
\frac{T_{e}-T_{i}}{R}+Q_{\text {lights }}-Q_{A / C}+C\left(\frac{d 0}{d t}-\frac{d T_{i}}{d t}\right)=0
$$

This can be expressed as:

$$
\frac{d T_{i}}{d t}=\frac{1}{C} \frac{T_{e}-T_{i}}{R}+\frac{1}{C}\left(Q_{\text {lights }}-Q_{A / C}\right)
$$

The term:

$$
\frac{T_{e}-T_{i}}{R}
$$

Represents the total heat flow, $Q_{T}$, into the house. This term can be computed for each surface of the house. That is:

$$
Q_{T}=\frac{T_{e_{-} s w}-T_{i}}{R_{s w}}+\frac{T_{e_{\_} n w}-T_{i}}{R_{n w}}+\frac{T_{e_{\_} e w}-T_{i}}{R_{e w}}+\frac{T_{e_{-} w w}-T_{i}}{R_{w w}}+\frac{T_{e_{-} s r}-T_{i}}{R_{s r}}+\frac{T_{e_{-} s w}-T_{i}}{R_{s w}}+\frac{T_{e_{-} n r}-T_{i}}{R_{n r}}
$$

where $T_{e_{-} s w}$ represents the Sol-Air temperature of the south wall. The same notation is used for all the other terms in the equation. Then, the differential equation can be expressed as:

$$
\frac{d T_{i}}{d t}=\frac{1}{C} Q_{T}+\frac{1}{C}\left(Q_{\text {lights }}-Q_{A / C}\right)
$$

The temperature controller is implemented in the model with a thermostat with hysteresis. For instance, for the cooling mode, $Q_{A / C}$, that is, alternates between zero and the rating of the air conditioning unit (in this simulation, 3.5 tons or $42000 \mathrm{Btu} / \mathrm{h}$ ). Heat is withdrawn from the house at rate $Q_{A / C}$ when the temperature exceeds the upper thermostat limit, and returns to zero when the temperature drops below the lower thermostat limit. In all the simulations performed here the thermostat setting is $74^{\circ} \mathrm{F}$ and $76^{\circ} \mathrm{F}$. Q $Q_{\text {lights }}$ is a constant heat gain inside the house of $1000 \mathrm{~W}$, reflecting lights and other appliances. 
In order to obtain specific results, dimension of the hypothetical house are selected. The house is a 2800 sq. $\mathrm{ft}$, house, with the following characteristics:

east-west dimension: 93'

north-south dimension: 30 '

These dimensions produce a house whose north and south walls are 930 sq. ft., and the east and west walls are $450 \mathrm{sq}$. ft. The north-facing and south facing roofs have an area of $1674 \mathrm{sq}$. ft. To simplify the calculations, the roof has no overhang. The simulation is performed with the southfacing roof shaded by the PV arrays, in which case the roof only receives diffuse solar radiation, and with no shading, receiving full direct radiation. Monthly radiation for the Phoenix is obtained from Rapp [4]. This monthly radiation is converted into an instantaneous irradiation function, modeled as a quadratic function. That is, irradiation begins at sunrise, increasing until zenith time, and then decreases to zero, at sunset. An adjustment factor of 0.92 is used to modify the instantaneous insolation function, to make its integral match the published monthly radiation. In addition, instantaneous insolation used in the simulation is further attenuated by cloud cover, using the function reported in by Rapp [4] and shown in Figure 3.

Figure 3: Attenuation factor used for cloud cover. From Rapp [4].

3-hour interval, outside temperature and cloud cover, for the Phoenix area (year 1990, 1991), and obtained from NOAA [5] is used in the simulation. Data from these years was used because it was available in electronic form. The author, in connection with another energy study, had previously transcribed printed data sheets corresponding to these years into a soft copy. (Note: There are databases where weather data is already in electronic format, but membership to the databases is required).

This section deals with the PV modules. Provided that the PV modules are oriented to optimize the output, the following losses apply for a fixed-latitude, tilt PV system. Amount of sunlight (generally the amount of sunlight available is proportional to the amount of energy produced by the array Ceteris Paribas). Modules (both poly-silicon and mono-silicon types) exhibit approximately a $12 \%$ conversion efficiency. In addition, there are other factors that affect the 
performance of a PV system, such as manufacturer's Standard Test Condition (STC), soiling effect, mismatch and wiring loss, DC to AC loss (inverter loss), and temperature loss.

PV manufacturers generally rate PV modules at STC parameters of $1000 \mathrm{~W} / \mathrm{m}^{2}\left(317(\mathrm{Btu} / \mathrm{hr}) / \mathrm{ft}^{2}\right.$, a solar cell temperature of $25^{\circ} \mathrm{C}$, and air mass value of 1.5 . The acceptable tolerance this rating is $+/-5 \%$ which means a module rated at STC can be expected to perform at around $95 \%$ at $25^{\circ} \mathrm{C}$. Soiling effect refers to the collection of dust on a PV array over time, which reduces the amount of sunlight available for energy production. Soiling is estimated to be able to reduce PV performance by approximately $93 \%$, leading the cumulative system performance, thus far, to a toll of $88.35 \%$. [6]

Additionally, module mismatch (which occurs as a result of imperfection of modules), can reduce the module efficiency by a further 5\%. DC to AC (conversion of DC to AC power) or inverter loss reduces the module performance by another $95-90 \%$. The combination of these effects brings the cumulative loss to a total of $77.5 \%$. The effect of temperature on module performance also degrades performance, since the module normally operates at a higher temperature than STC. It is customary to further de-rate the module by $88 \%$ due to temperature effects. The PV arrays are rack mounted, to insure minimal temperature increase. PV performance decreases as the temperature increases. In practice, the modules should be separated at least 4" from the roof [7].

Simulation

The simulation, (solution to the differential equation) is performed with TK-Solver [8], using the Runge-Kutta numerical integration function contained in their included library. The actual simulation is performed with a time step of $3 \mathrm{~min}$. Figure 4 shows the outside temperature, and the resulting inside temperature for the month of July.

Figure 4: Outside and inside house temperature for the month of July 
Results and Discussion

Each month is treated as a different entity. Heating or cooling mode is selected and applied through the entire month. This means that if cooling is the chosen mode for given month, there might be some short occurrences where the temperature could drop below the lower thermostat setting. It is assumed that the air conditioning unit is a heat pump with an Energy Efficiency Ratio (EEF) of 6, which is equivalent to a Coefficient of Performance (CF) of 1.75. Each simulation is performed with and without shading produced by the PV arrays. The results are shown in Table 1. Notice that shading has more effect on cooling load. The yearly cooling costs are reduced by $\$ 126$, while the heating cost increases by $\$ 25$. thus the shading has a net effect of reducing the yearly electric bill by approximately $\$ 100$, or $\$ 11 \%$. Notice that if net meeting is in effect, the utility buys needs to buy back the electricity that the customer puts in to the grid at the same rate that the customer buys it from the utility; the PV arrays will generate \$2254 annually.

Table 1: Simulation results

\begin{tabular}{|c|c|c|c|c|c|c|c|c|c|c|c|c|c|}
\hline & Jan & Feb & Mar & Apr & May & \begin{tabular}{|l|} 
Jun \\
\end{tabular} & Jul & Aug & Sep & Oct & Nov & Dec & Total \\
\hline $\begin{array}{l}\text { cooling } \\
\text { (C) or } \\
\text { heating } \\
\text { (H) }\end{array}$ & $\mathrm{H}$ & $\mathrm{H}$ & $\mathrm{H}$ & C & C & C & C & C & C & C & $\mathrm{H}$ & $\mathrm{H}$ & \\
\hline $\begin{array}{l}\text { cooling } \\
\text { cost (\$) } \\
\text { with no } \\
\text { PV } \\
\text { shading }\end{array}$ & & & & 51 & 80 & 133 & 130 & 112 & 90 & 50 & & & 646 \\
\hline $\begin{array}{l}\text { cooling } \\
\text { cost (\$) } \\
\text { with PV } \\
\text { shading }\end{array}$ & & & & 35 & 59 & 111 & 110 & 94 & 74 & 37 & & & 520 \\
\hline $\begin{array}{l}\text { heating } \\
\text { cost (\$) } \\
\text { with no } \\
\text { PV } \\
\text { shading } \\
\end{array}$ & 77 & 31 & 32 & & & & & & & & 36 & 86 & 262 \\
\hline $\begin{array}{l}\text { heating } \\
\text { cost (\$) } \\
\text { with PV } \\
\text { shading }\end{array}$ & 84 & 35 & 36 & & & & & & & & 40 & 92 & 287 \\
\hline $\begin{array}{l}\text { Cost (\$) of } \\
\text { energy } \\
\text { generated } \\
\text { by PV }\end{array}$ & 105 & 115 & 166 & 222 & 278 & 286 & 260 & 238 & 202 & 172 & 119 & 91 & 2254 \\
\hline
\end{tabular}

Conclusions

The shading provided by the PV array reduces the net utility bill by $11 \%$. Thus, providing shading to the house is a good investment, whether through the PV modules or other devices, especially in the Southwest, where cooling load dominate the total bill. Future efforts should include the effect of the overhang and also use a thermal model that takes into consideration wind speed. 
References

1. "Shading effects due to nearby buildings and energy Implications", by Joseph C. Lam Energy Conversion \& Management 41 (2000) 647-659

2. 2001 ASHRAE Handbook, Fundamentals, I-P Edition

3. Macia, Narciso F. and Thaler, George J., Modeling and Control of Dynamic Systems, Thomson Delmar Learning, 2004.

4. Rapp, Donald, Solar Energy, Prentice-Hall, 1981

5. National Oceanic and Atmospheric Administration

6 California Energy Commission Energy Technology Development Division. (2001). A Guide to Photovoltaics (PV) System Design and Installation. 500-01-020. San Ramon, California. Prepared by Endecon Engineering.

7. Persona Communications with Dr. Mani of the ASU Photovoltaic Testing laboratory. 8. Universal Technical Systems, Rockford, IL.

\section{NARCISO F. MACIA}

Narciso F. Macia is an Associate Professor in the Department of Electronics and Computer Engineering Technology, at Arizona State University at the Polytechnic campus (formerly ASU East). He received B.S. and M.S. degrees in mechanical engineering in 1974 and 1976 from the University of Texas at Arlington. He also received a Ph.D. in electrical engineering from Arizona State University in 1988. 